\title{
Awareness on Nutritional Anemia and its Prevention among Adolescent Girls
}

\author{
Santhi P. ${ }^{1}$, G. Ambujam² \\ ${ }^{1}$ Research Scholar, Associate Professor, Vinayaka Mission's College of Nursing, Karaikal, Vinayaka Missions' \\ Research Foundation-DU, Salem, ${ }^{2}$ Dean \& Professor of Surgery, Research Guide, Vinayaka Mission's Medical \\ College, Karaikal, Vinayaka Missions'Research Foundation-DU, Salem
}

\begin{abstract}
Background: Adolescence is the period of rapid growth with physical \& physiological development and profound biological, emotional, social, and cognitive changes in human beings. Nutritional anemia is the common \& worldwide public health problem among adolescent girls and overall prevalence of nutritional anemia varies from $40-90 \%$. It may produce adverse effects like increased risk of morbidity and mortality and affects adolescent's future health.
\end{abstract}

Objective: This study aimed to assess the awareness on nutritional anemia and its prevention among adolescent girls.

Method: A non experimental descriptive design was adopted to assess awareness on nutritional anemia and its prevention among adolescent girls at Keezhakasakudi, Karaikal. A total of 60 adolescent girls between 10-15 years of age were selected by convenience sampling technique. Data was collected by using self structured interview schedule. Both descriptive and inferential statistics were used to analysis the gathered data.

Results: The study results reported that the majority 63\% (38) of adolescent girls had inadequate awareness, $27 \%$ (16) had moderately adequate awareness and only $10 \%$ (6) had adequate awareness on nutritional anemia and its prevention. The overall mean was 9.6 with standard deviation \pm 2.49 . The results of the present study also revealed that there was statistically significant association between level of awareness on nutritional anemia with age of the adolescent girls.

Conclusion: Nutritional anemia as the major non communicable disease and contributing negative impact on health, it necessitates the need to organize counseling programs to adolescent girls in schools and colleges with much emphasis on impact of nutritional anemia on future health.

Keywords: Awareness, Nutritional anemia, Prevention, Adolescent girls.

\section{Introduction}

Adolescence is the period of lifetime between 10 to 19 years of age as per WHO. It is the period where

\author{
Corresponding Author: \\ Mrs. P. Santhi, M.Sc. (N) \\ Associate Professor, Vinayaka Mission's College \\ of Nursing, Karaikal, Vinayaka Missions' Research \\ Foundation-DU, Salem \\ e-mail: psanthi03@gamil.com
}

there is rapid growth with physical \& physiological development and profound biological, emotional, social, and cognitive changes in human beings. ${ }^{[1]}$ Adolescent period forms the basis of development of many habits which may persist for lifelong including eating habits. Adolescence needs extra nutrients to meet their increasing demands of rapid growth and development. Majority of adolescents develop nutritional anemia due to lack of necessary nutrients in the diet, imbalanced diet, craving for junk foods and fast foods, having the habit of skipping meals and peer group influence 
in deciding eating choices. Nutritional anemia is a universal problem of adolescent girls particularly in low economic under developed and developing countries including India. ${ }^{[2]}$ Nutritional anemia is the common \& worldwide public health problem among adolescent girls and overall prevalence of nutritional anemia among adolescent girls in Northwest Ethiopia was $25.5 \%{ }^{[3]}$. Prevalence of anemia among adolescent girls differs in different parts of India and findings of research studies revealed that $35.9 \%$ in Karaikal ${ }^{[4]} 48.63 \%$ in Tamil $\mathrm{Nadu},{ }^{[5]} 50 \%$ in Bihar, ${ }^{[6]} 78.3 \%$ in Mumbai, ${ }^{[7]} 78.5 \%$ in UttarPradesh, ${ }^{[8]} 78.8 \%$ in Odisha, ${ }^{[9]} 84.3 \%$ in rural south India ${ }^{[10]}$ and $90 \%$ in Nagpur. ${ }^{[11]}$ Low socioenomic class, dietary diversity, household food status, living status, literacy level, parasitic infestation, haemolytic disease, malaria, menstrual abnormalities and bioavailability of iron are the contributing factors for anemia among adolescent girls ${ }^{[12]}$ Nutritional anemia in adolescent girls may lead to decreased oxygen carrying capacity of the blood which in turn caused decreased work capacity, inability concentrate in academic activity and problems in menstruation ${ }^{[13]}$ It may also produce impact on their future life when the adolescence enters into reproductive age; it may produce adverse effects like increased risk of morbidity and mortality during antenatal, intra natal \& postnatal period and also low birth weight babies. ${ }^{[14]}$ Hence it is necessary to know the existing level of awareness among adolescent girls in order to adhere to the preventive steps to reduce its prevalence.

Statement: A study to assess the awareness of nutritional anemia and its prevention among adolescent girls at Keezhakasakudi village, Karaikal

\section{Objectives:}

- To assess the awareness on nutritional anemia and its prevention among adolescent girls

- To associate the level of awareness on nutritional anemia and its prevention with demographic variables of adolescent girls.

\section{Materials and Method}

A non experimental descriptive design was adopted to assess awareness on nutritional anemia and its prevention among adolescent girls at Keezhakasakudi village, Karaikalfor this study. Convenience sampling technique was used to select 60 adolescent girls of 10-15 years for the study. A pretested self structured interview schedule was used to collect the data from the participants. The tool consisted of two selections. Section A consisted of 12 items on demographic profile of adolescent girls such as age, educational, mother's education \& occupation, father's education \& occupation, monthly family income, religion, type of family, No. of children, Age at menarche and mode of getting information related to nutritional anemia. Section B included 20 items of multiple choice questions regarding awareness on nutritional anemia and its prevention which included meaning, causes, clinical features and prevention of nutritional anemia. The reliability of the tool was tested by split half method. ( $\mathrm{r}=0.8$ ) Pilot study was carried out for six participants to check the feasibility and practicability of the study. It was found feasible to conduct the study. After explaining the purpose of the study, informed oral consent was obtained from each adolescent girl. Self structured interview schedule was administered to each participant to collect the data. It took $15-20$ minutes to collect information from each participant. Descriptive statistics such as mean, mean percentage, standard deviation were used to analysis level of awareness. Inferential statistics such as chisquare was used to associate the level of awareness with demographic variables.

\section{Results}

- The study results revealed that the majority $35 \%$ (21) of the adolescent girls were between the ages of 14-15 years

- The highest 35\% (21) of study participants were in $6^{\text {th }}$ standard and the least $16.7 \%(10)$ were in $9^{\text {th }}$ standard.

- With regard to the mother's educational status, the majority 25\% (15) were illiterate and the less $15 \%$ (9) had primary and secondary education.

- Based on the mother's occupation the highest $28.3 \%$ (17) were government employees and 20\% (12) had self employment.

- With respect to father's educational level, the greater $38.3 \%$ (23) had primary education and only $10 \%$ (6) had higher secondary education and $31.7 \%$ (19) of the study participant's father were employed in private organization.

- The majority $30 \%(17)$ had monthly family income above Rs. 15,001/- and the least 20\%(12) had monthly family income less than Rs. 5000/-

- The maximum 75\% (45) of study participants belonged to Hindu religion and living in a nuclear family. 
- The study result also revealed that the highest $56.7 \%$ (34) of family had only one child in their family.

- The majority of adolescent girls 35\% (21) had menarche at the age of 13-16 years.

- The maximum $28.3 \%$ (17) of adolescent girls reported that the major source of information obtained was through Radio and Television

- The results of the present study revealed that the mean value of awareness on meaning of nutritional anemia was 1.45 , on causes of nutritional anemia were 2.15 , on clinical features were 2.55 and on prevention were 4.45 .

- The study results also reported that the majority $63 \%$ (38) of adolescent girls had inadequate awareness, $27 \%$ (16) had moderately adequate awareness and only $10 \%$ (6) had adequate awareness on nutritional anemia and its prevention. The overall mean was found to be 9.6 with standard deviation \pm 2.49 .

- The results of the present study also revealed that there was statistically significant association between the level of awareness on nutritional anemia with only one demographic variable the age of the adolescent girls $(\chi 2=10.2)$ at $p<0.05$ and there was no association between awareness on nutritional anemia with other demographic variables such as educational status, parents educational status and occupation, monthly family income, type of family, number of children in the family, religion and the sources of information.

\section{Discussion}

The result of present study revealed that the highest percentage of adoldescnt girls $68 \%(38)$ had inadequate awareness on nutritional anemia and its prevention, $27 \%(16)$ had moderately adequate awareness and only $10 \%(6)$ had adequate awareness on nutritional anemia and its prevention. This was supported by the study conducted by Gracy. S \& N Junior Sundresh ${ }^{[15]}$ on knowledge regarding prevention and management of anemia among adolescent girls, in Bhadravathi showed

that majority of adolescent girls (57\%) had inadequate knowledge, only ( $43 \%$ ) had moderate level of knowledge and none of the adolescent girls had adequate knowledge. The findings of the present study corresponded with another study conducted by Premaletha T \& Safeena $S^{[16]}$ on Prevalence of anaemia and knowledge of adolescent girls regarding anaemia in higher secondary Schools of Thiruvananthapuram corporation which reported that $51 \%$ had poor knowledge, $38 \%$ had average knowledge and only $11 \%$ had good knowledge regarding anemia.

The findings of present study revealed that the overall mean of awareness on nutritional anemia was found to be 9.6 which showed moderate awareness. Still there is widespread prevalence of anemia among adolescent girls and there is a need to change the attitude and behavior of adolescents to combat anemia. The findings of present study was found less than the study results conducted by Chandrasekhar $\mathrm{M}$ et al ${ }^{[17]}$ on assessment of Knowledge of Adolescent Girls Regarding the Prevention of Iron Deficiency Anemia in Selected Rural Areas of Mysore which found the mean knowledge score of adolescent girls was 12.58 . Hence it is necessary to organize health education programme with more focus on specific issues and information on anemia such as healthy dietary pattern including intake iron and vitamin $\mathrm{C}$ rich foods, reducing junk foods, fast foods and avoiding tea and coffee to enhance iron absorption and proper utilization of deworming and iron supplementation provided by school health programme.

Table 1: Percentage distribution of level of awareness on nutritional anemia and its prevention among adolescent girls

\begin{tabular}{|l|c|c|}
\hline Level of Awareness & Frequency & Percentage \\
\hline Inadequate & 38 & 63 \\
\hline Moderately adequate & 16 & 27 \\
\hline Adequate & 6 & 10 \\
\hline Total & $\mathbf{6 0}$ & $\mathbf{1 0 0}$ \\
\hline
\end{tabular}


Table 2: Mean, standard deviation \& mean percentage of level of awareness on nutritional anemia and its prevention

\begin{tabular}{|l|c|c|c|c|}
\hline Items & Maximum attainable score & Mean & SD & Mean Percentage \\
\hline Meaning & 3 & 1.45 & 1 & 13.68 \\
\hline Causes & 5 & 2.15 & 1.35 & 20.28 \\
\hline Clinical Features & 4 & 2.55 & 1 & 24.06 \\
\hline Prevention & 8 & 4.45 & 1 & 41.98 \\
\hline
\end{tabular}

\section{Conclusion}

Nutritional anemia as the major non communicable disease is prevailing among adolescent girls and contributing negative impact on physical health as well as their academic performance and cognitive ability. It is necessary to create awareness on nutritional anemia and its prevention with multiple audio visual aids to enhance desired behavior change among adolescent girls. This also necessitates the need to organize counselling programs to adolescent girls in schools and colleges with much emphasis on impact of nutritional anemia on future health.

\section{Conflict of Interest: Nil}

\section{Source of Funding: Self}

Ethical Clearance: Taken from Institutional Research committee.

\section{References}

1. Jodhun BM, Pem D, Jeewon R. A systematic review of factors affecting energy intake of adolescent girls. Afr Health Sci. 2016;16(4):910-922.

2. Gonete et al. Prevalence and associated factors of anemia among adolescent girls attending high schools in Dembia District, Northwest Ethiopia. Archives of Public Health 2018; 76:79

3. Mujibur Rahman. K. et al. Prevalence of Iron Deficiency Anemia among Reproductive Age Group Women.Journal of Clinical and Diagnostic Research.2019Mar; 13(3): LC06-LC106. Available from DOI: $10.7860 / J C D R / 2019 / 36623.12706$

4. ChandrakumariAS, SinhaP, SingaraveluS, Jaikumar S. Prevalence of Anemia Among Adolescent Girls in a Rural Area of Tamil Nadu, India. J Family Med Prim Care. 2019 Apr;8(4):1414-1417. Available from DOI: $10.4103 /$ jfmpc.jfmpc_140_19.
5. Kumari R, Bharti RK, Singh K, Sinha A, Kumar S, Saran A, Kumar U. Prevalence of Iron Deficiency and Iron Deficiency Anaemia in Adolescent Girls in a Tertiary Care Hospital. J Clin Diagn Res. 2017 Aug;11(8):BC04-BC06. Available fromDOI: 10.7860/JCDR/2017/26163.10325.

6. Srinivas V, Mankeshwar R. Prevalence and determinants of nutritional anemia in an urban area among unmarried adolescent girls: A communitybased cross-sectional study. Int J Med Public Health. 2015;5:283-8.

7. Arya AK, Lal P, Kumar N, Barman S. Prevalence of anemia among adolescent girls in an urban slum of Kanpur, Uttar Pradesh. Int J Med Sci Public Health. 2017;6(9):1378-1381.

8. Pattnaik S Patnaik L Kumar A Sahu T. Prevalence of Anemia among adolescent girls in a rural area of Odisha and its epidemiological correlates. Indian Journal of Maternal and Child Health.2012;15(1)

9. Anandi. C \& Yoganandh. Prevalence and factors influencing anaemia among adolescent females in rural area of South India. Indian Journal of Basic and Applied Medical Research; 2017: 6(3): 258265

10. Upadhye JV et al. Assessment of anaemia in adolescent girls. Int J ReprodContracept Obstet Gynecol. 2017;6(7):3113-3117

11. Rekha Kumari et al., Prevalence of Iron Deficiency and Iron Deficiency Anaemia in Adolescent Girls in a Tertiary Care Hospital, Bihar. Journal of Clinical and Diagnostic Research. 2017. 11(8): 04-06

12. Gowdhaman. N, C Kameshvell \& Devaki Vijayalakshmi. Prevalence of Anaemia and its associated factors among children in suburban Puducherry - A cross sectional study. 2017. Accessed through http://www.semanticscholar.org/ author[Accessed on 12.01.2020] 
13. Abbaspour N, Hurrell R, Kelishadi R. Review on iron and its importance for human health. J Res Med Sci. 2014;19(2):164-74.

14. Kumari $\mathrm{S}$ et al. Maternal and severe anaemia in delivering women is associated with risk of preterm and low birth weight: A cross sectional study from Jharkhand, India. One Health. 2019; 19(8):100098. Available from DOI: $10.1016 / \mathrm{j}$. onehlt.2019.100098.

15. Gracy. S \& N Junior Sundresh. Knowledge regarding prevention and management of anemia among adolescent girls, in Bhadravathi. Global Journal for Research Analysis. 2017; 6(7):54-55
16. Premaletha T, Safeena S. Prevalence of anaemia and knowledge of adolescent girls regarding anaemia. J PaediatrNurs Sci. 2019;2(3):74-6.

17. Chandrasekhar $M$ et al. Study to assess the Knowledge of Adolescent Girls Regarding the Prevention of Iron Deficiency Anemia in Selected Rural Areas of Mysore with a View to Develop an Information BookletonPrevention and Management of Iron Deficiency Anemia. Asian J. Nur. Edu. and Research. 2016; 6(1): 74-78. Available from DOI: 10.5958/2349-2996.2016.00015.X 